\title{
Solution for the neglected problem of snake bite envenoming in sri lanka
}

\begin{abstract}
The snake bites are in the Sri Lankan population at risk; however, there should be targeted programs to educate people on these aspects. Studying the awareness and perceptions related to such issues of risk groups is important in designing community based interventional programs on snakebite towards combating the global burden of snakebite. Such information is lacking on the farming community of Sri Lanka. Therefore this mini review will highlight the importance of the snake bites awareness in Sri Lanka. Snake bites are well known medical emergencies in many parts of the world, especially in rural areas. Agricultural works and children are the most effected victims on snake bites in Sri Lanka. Sri Lanka is considered as a country with highest morbidity rates of snakebites in the whole world. It is highest in North Central Province, compared to any other areas in Sri Lanka, due to large faming community. However, the true scale of mortality and acute and chronic morbidity from snake-bite remains uncertain because of inadequate reporting in almost every part of the region. The incidence of snake bite mortality is particular high in this country and according to national statistics; the annual snake bite incidence in Sri Lanka ranges 3500040000 during past 10 years.
\end{abstract}

Keywords: snake bite, venomous snakes, morbidity, mortality
Volume I Issue 2 - 2015

\author{
Faiz Marikar \\ General Sir John Kotelawela Defence University, Sri Lanka
}

Correspondence: Faiz Marikar, General Sir John Kotelawela Defence University, Kandawala Estate, Rathmalana, Sri Lanka, Tel 94 I 2413900, Email faiz.marikar@fulbrightmail.org

Received: October 19,2014 | Published: April 16,2015

\section{Mini review}

The venomous snakes are responsible for a high incidence of snakebite morbidity and mortality in Sri Lanka as mentioned above. Cobra/Naya (Naja naja); Common krait/ Magamaruwa, Thel Karawala (Bungarus caeruleus); Sri Lanka krait/ Mudu Karawala (Bungarus ceylonicus); Russells's viper/ Thith Polanga (Daboia russelii); and Saw scale viper/ weli Polanga (Echis carinatus) are considered as highly toxic. Hump nose viper/ Kunakatuwa (Hypnale hypnale and other 2 species); Green pit viper/ Pala Polanga (Trimeresurus trigonocephalus) are considered as intermediate toxic and may cause deadly. Approximately the 13 species of marine snakes which inhabit the coastal waters and estuaries around the island are considered as venomous.

Clinicians have for a long time witnessed the tragedy of injury in Sri Lankan soil, disability, and death from snake bite that is a daily occurrence. ${ }^{1}$ To many people living in North Central Province, including some of the Sri Lankans poorest communities, snake bite is an ever present occupational risk and environmental hazard, an additional penalty of poverty. Like sand fly disease currently emerging, dengue, tuberculosis, and parasitic diseases, the risk of snake bite is always present. Unlike many of other community based health risks, Sri Lanka is having high percentage of human suffering caused by snake bite remains unrecognized, and even neglected by development agencies and even government. ${ }^{1}$

In the tropical developing country like Sri Lanka where snake bites occur most commonly, there are few reliable incidence data. ${ }^{2}$ Most of the familiar methods for snake bite treatment, both western and "traditional/ indigenous"; have been found to result in more harm (risk) than good (benefit). Their use should be discouraged and they should never be allowed to delay the movement of the patient to medical care at the hospital or dispensary. Main reason is there are no records of patients who have been treated by various indigenous methods from official database statistics, more over the deaths caused by the snakes from the villages are not being tabulated by the ministry. ${ }^{3}$ Accepting these limitations, the fragmentary evidence available suggests that several thousand bites and envenoming occur; Sri Lanka each year, with several thousand deaths. Diagnosis of the species of snake responsible for the bite is important for optimal clinical management. This may be achieved by identifying the dead snake or by inference from the "clinical syndrome" of envenoming. Envenoming resulting from snake bites will not be neglected and it is indeed an important public health hazard in many regional countries in the Asia, particularly high living was observed in tropical and subtropical countries. Although antivenoms are being produced and brought to this country mainly by Indian various laboratories, the morbidity and mortality by snake bite envenoming causing a great impact on the population and on health-care systems, especially in Sri Lanka, due to we don't produce antivenom for specific snake species, and we always depend on the foreign produced antivenom. Unfortunately, public health authorities, nationally and internationally, have given little attention to this problem, relegating snake bite envenoming to the category of a major neglected disease of this country. ${ }^{3}$

The intravenous administration of animal-derived (mostly horse or sheep) antivenoms is the mainstay and the only specific treatment of snake bite envenoming. ${ }^{3}$ Many laboratories produce antivenoms using various methodologies, that simple method we can adapt for develop antivenom easily and cheaply. Clinical investigations in Government hospitals have established antivenoms are highly effective in the neutralization of toxins responsible for systemic effects such as hemorrhage, coagulopathy, and hemodynamic disturbances. ${ }^{2}$ Similarly, a rapid reversal of neurotoxicity caused by postsynaptic neurotoxins in elapid envenomings is well established and I would like to request from the general public to go for the treatment at General Hospital for snake bite. ${ }^{3}$ In spite of success rate of antivenoms in the therapy of snake bite envenoming, various number of research teams are working in Sri Lanka, especially NGOs and Universalities 
are trying to improve the quality of antivenoms and specific for snakes which live in Sri Lankan tertiary using different approaches:? new immunization techniques using DNA immunization or the use of extract specific region of snake toxins as antigens instead of the whole venom. Therefore envenoming is a matter of needy and worthy project to promote international collaboration with the World Health Organization involving national and regional health organizations and diverse public-private partnerships in order to accomplish to make world safe with snake bite treatment. ${ }^{3}$

\section{Conclusion}

As a concluding remark high awareness of snakebite prevention and first aid presumably is due to the fact that snakebite is an important part of the life of the studied population. Furthermore, the low priority given for snakebite prevention in community health promotion programs in Sri Lanka has presumably played a role in not bringing the knowledge into practice. However, unless the important knowledge gaps in the socio epidemiology of snakebites are filled and permanent snakebite prevention programs established, chances of changing practices towards minimizing snakebite appear slim in Sri Lanka.

\section{Acknowledgements}

None.

\section{Conflict of interest}

The author declares no conflict of interest.

\section{References}

1. Arshad Anjum, Munawwar Husain, Shaukat A Hanif, et al. Epidemiological Profile of Snake Bite at Tertiary Care Hospital, North India. J Forensic Res. 2012;3(4):1-5.

2. Yang M. Confronting the Neglected Problem of Snake Bite Envenoming: The Need for a Global Partnership. 2014.

3. Gutierrez JM, Theakston RD, Warrell DA. Confronting the neglected problem of snake bite envenoming: the need for a global partnership. PLoS Med. 2006;3(6):e150. 